\title{
Correction to: Buoyancy-driven propagation of an isolated fluid-filled crack in rock: implication for fluid transport in metamorphism
}

\author{
Yoshito Nakashima ${ }^{1}$
}

Published online: 30 January 2018

๑) Springer-Verlag GmbH Germany, part of Springer Nature 2018

\section{Correction to: \\ Contrib Mineral Petrol (1993) 114(3):289-295 https://doi.org/10.1007/BF01046532}

The article [Buoyancy-driven propagation of an isolated fluid-filled crack in rock: implication for fluid transport in metamorphism], written by [Yoshito Nakashima], was originally published Online First without open access. After publication in volume [114], issue [3], page [289-295] [National Institute of Advanced Industrial Science and Technology Center] requested that the article be Open Choice to make the article an open access publication. Post-publication open access was funded by [National Institute of Advanced
Industrial Science and Technology Center]. Further details may be found at [https://link.springer.com/article/10.1007/ BF01046532]. The article is forthwith distributed under the terms of the Creative Commons Attribution-NonCommercial 4.0 International License (http://creativecommons.org/ licenses/by-nc/4.0/), which permits any noncommercial use, duplication, adaptation, distribution and reproduction in any medium or format, as long as you give appropriate credit to the original author(s) and the source, provide a link to the Creative Commons license and indicate if changes were made.
Yoshito Nakashima

nakashima.yoshito@aist.go.jp

1 Institute of Applied Physics, University of Tsukuba,

Tsukuba, Ibaraki 305, Japan 